\title{
Hubungan Tingkat Kepatuhan ANC dengan Kejadian Anemia, Makrosomia, dan Gemelli pada Kasus Pendarahan Postpartum
}

\author{
Azizah Nurdin', Yusril Ihsanul $\mathbf{M}^{2 *}$, Najamuddin Andi Palancoi ${ }^{3}$ \\ ${ }^{1}$ Departemen Histologi, Program Studi Pendidikan Dokter, Fakultas Kedokteran dan Ilmu Kesehatan, UIN \\ Alauddin Makassar \\ ${ }^{2}$ Program Studi Sarjana Kedokteran, Fakultas Kedokteran dan Ilmu Kesehatan, UIN Alauddin Makassar, \\ Makassar, Indonesia \\ ${ }^{3}$ Departemen Biomedik, Fakultas Kedokteran dan Ilmu Kesehatan, UIN Alauddin Makassar, Makassar, \\ Indonesia
}

*Corresponding Author. E-mail: yusrilihsanulmukarram@gmail.com, Mobile number: +62 812-4384-9959

\begin{abstract}
ABSTRAK
Latar Belakang :Antenatal care $(A N C)$ merupakan pelayanan ibu hamil yang dilakukan selama kehamilan oleh tenaga kesehatan profesional. Keidakpatuhan ANC merupakan salah satu faktor risiko tidak langsung mengakibatkan terjadinya komplikasi kehamilan seperti anemia, makrosomia dan gemelli. Tujuan penelitian ini untuk mengetahui apakah ada hubungan antara tingkat kepatuhan ANC dengan kejadian anemia, makrosomia dan gemelli.

Metode : Penelitian ini menggunakan design penelitian yaitu analitik retrospektif dengan pendekatana Cross-sectional. Populasi penelitian ini adalah semua ibu hamil yang mengalami perdarahan postpartum di RSUD Syekh Yusuf Tahun 2018. Teknik pengambilan sampel menggunakan total sampling.

Hasil : penelitian menunjukkan bahwa terdapat hubungan antara tingkat kepatuhan ANC dengan kejadian anemia dengan nilai $p$-value sebesar 0,004. Sedangkan variabel lain didapatkan hasil tidak terdapat hubungan yang signifikan, yaitu hubungan tingkat kepatuhan ANC dengan kejadian makrosomia didapatkan nilai $p$-value sebesar 0,759, dan hubungan tingkat kepatuhan ANC dengan kejadian gemelli didapatkan nilai $p$-value sebesar 0,085.

Kesimpulan: Terdapat hubungan antara tingkat kepatuhan ANC dengan kejadian anemia.
\end{abstract}

Kata kunci: Antenatal care; anemia; makrosomia; gemelli

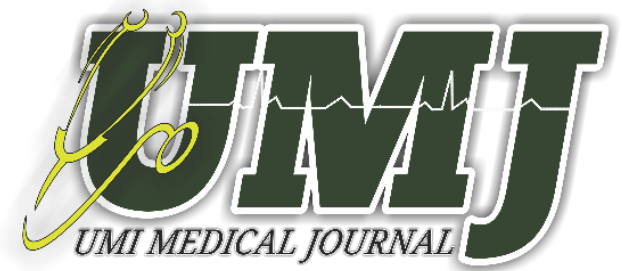

Article history:

Received: 01 Mei 2020

Accepted: 23 Juni 2020

Published by :

Address:

Fakultas Kedokteran

J1. Urip Sumoharjo Km. 5 (Kampus II UMI)

Universitas Muslim Indonesia

Phone:

Makassar, Sulawesi Selatan.

+6282293330002

Email:

medicaljournal@umi.ac.id 


\section{ABTRACT}

Background: Antenatal care (ANC) is a service for pregnant women carried out during pregnancy by health professionals. ANC noncompliance is one of the indirect risk factors for pregnancy complications such as anemia, macrosomia and gemelli. The purpose of this study was to determine whether there was a relationship between the level of ANC adherence with the incidence of anemia, macrosomia and gemelli.

Methods: This study used a retrospective analytical research design with a cross-sectional approach. The population of this study were all pregnant women who experienced postpartum hemorrhage at Syekh Yusuf Hospital in 2018. The sampling technique used total sampling.

Results: The study showed that there was a relationship between the level of ANC compliance with the incidence of anemia with a p-value of 0.004. Meanwhile, the other variables showed that there was no significant relationship, namely the relationship between the ANC compliance level and the macrosomia incidence obtained a p-value of 0.759 , and the correlation between ANC compliance level and the Gemelli incident obtained a p-value of 0.085 .

Conclusion: relationship between ANC adherence level and anemia incidence.

Keywords : Antenatal care; anemia; macrosomia; gemelli

\section{PENDAHULUAN}

Kesehatan ibu dan anak merupakan salah satu pokok sasaran kementrian kesehatan dalam peningkatan kesehatan di Indonesia yang dapat nilai dari tingkat mortalitas dan morbiditas ibu dan anak.(1) Menurut WHO, pada tahun 2015 angka kematian ibu (AKI) sebanyak 303.000 atau 239/100.000 kelahiran hidup baik selama maupun setelah kehamilan dan persalinan.(2) Di Indonesia, pada tahun 2015 didapatkan angka kematian ibu (AKI) sebanyak 305/100.000 kelahiran hidup.(3) Kemudian Di Sulawesi Selatan angka kematian ibu (AKI) pada tahun 2016 didapatkan sebanyak 153 orang atau 103/100.000 kelahiran hidup.(4)

Penyebab tingginya angka kematian ibu ini adalah perdarahan, infeksi, tekanan darah tinggi selama kehamilan, partus lama, dan abortus.(3) Penyebab terbanyak dari kematian ibu ini adalah perdarahan sebesar 30,3\%, dimana jenis perdarahan tersering menyebabkan kematian ibu di dunia adalah perdarahan post partum yaitu sebesar $35 \%$.(5) Di Indonesia, menurut data dari kementerian kesehatan pada tahun 2017 dikatakan bahwa ada 3 penyebab tersering kematian ibu salah satunya adalah perdarahan.(3) Di RSUD Syekh Yusuf Kabupaten Gowa pada tahun 2018, didapatkan kasus perdarahan postpartum sebanyak 82 kasus.

Perdarahan postpartum merupakan suatu masalah besar pada ibu hamil karena dapat mengakibatkan terjadinya kematian pada ibu. Perdarahan postpartum ini dapat disebabkan oleh banyak faktor resiko salah satunya adalah karena tidak patuhnya ibu hamil dalam memeriksakan kehamilannya (Antenatal care). Dengan melakukan ANC yang rutin dan patuh Ibu hamil dapat terhindar dari masalah baik dalam kehamilannya maupun dalam proses persalinannya serta pada masa nifasnya contoh masalah yang dapat timbul dan menjadi faktor resiko dari perdarahan postpartum adalah anemia, makrosomia, dan gemelli, sehingga pelayanan ANC ibu hamil akan di periksa terkait masalah dan keluhannya sehingga semua keluhan dan masalah dapat di hilangkan.(3) 
Sebagaimana dalam penelitian yang dilakukan oleh Ratna Puspita Sari pada tahun 2017 yang menyatakan bahwa terdapat hubungan antara frekuensi kunjungan ANC dengan kejadian perdarahan postpartum. Pada penelitiannya juga menyatakan bahwa ibu dengan ANC lengkap atau teratur dapat mengurangi terjadinya komplikasi terkhusus adalah perdarahan postpartum.(6)

Kasus perdarahan postpartum ini disebabkan oleh banyak hal termasuk diantaranya adalah, anemia, makrosomia dan gemalli, sehingga, peneliti tertarik untuk melakukan penelitian terkait hubungan tingkat kepatuhan ANC dengan kejadian anemia, makrosomia, dan gemelli pada kasus perdarahan postparum di RSUD Syekh Yusuf kabupaten Gowa.

\section{METODE}

Metode yang digunakan dalam penelitian ini adalah analitik retrospektif dengan rancangan cross sectional. Rancangan penelitian ini digunakan untuk mengetahui hubungan variabel dependen yaitu anemia, makrosomia, dan gemelli dengan variabel independen yaitu kepatuhan ANC ibu hamil. Penelitian dilakukan bulan Januari 2020 di Rumah Sakit Umum Daerah (RSUD) Syekh Yusuf Kabupaten Gowa dan sudah mendapatkan kelayakan etik dengan nomor E.011/KEPK/FKIK/XII/2019 tertanggal 18 Desember 2019. Populasi pada penelitian ini adalah seluruh ibu yang mengalami perdarahan postpartum di RSUD Syekh Yusuf Kabupaten Gowa tahun 2018. Pengambilan sampel dilakukan dengan menggunakan teknik total sampling dengan jumlah sampel sebanyak 82 sampel.

Sumber data yang digunakan dalam penelitian ini adalah data sekunder. Data sekunder diperoleh dari rekam medik Rumah Sakit Ibu Umum Daerah (RSUD) Syekh Yusuf Kabupaten Gowa.

Data yang diperoleh kemudian dianalisis menggunakan software IBM SPSS 23. Analisis hubungan antara variable dengan menggunakan uji Chi-square.

HASIL

Tabel 1. Distribusi Sampel Berdasarkan Karakteristik Sampel

\begin{tabular}{lcc}
\hline \multicolumn{1}{c}{ Parameter } & $\mathbf{N}$ & $\%$ \\
\hline Anemia saat hamil & & \\
a. Iya & 57 & 69,51 \\
b. Tidak & 25 & 30,49 \\
\hline Makrosomia & & \\
a. Iya & 20 & 24,39 \\
b. Tidak & 62 & 75,61 \\
\hline Gemelli & & \\
a. Iya & 15 & 18,29 \\
b. Tidak & 67 & 81,71 \\
\hline Antenatal Care (ANC) & & 21,95 \\
a. Patuh & 18 & 78,05 \\
b. Tidak Patuh & 64 & \\
\hline
\end{tabular}




\begin{tabular}{lll}
\hline Perdarahan postpartum & & \\
Primer $(\leq 24$ jam $)$ & 55 & 67,07 \\
Sekunder $(>24$ jam $)$ & 27 & 32,93 \\
\hline
\end{tabular}

Berdasarkan Tabel 1, diketahui bahwa dari total 200 responden, distribusi responden berdasarkan Anemia saat hamil didaptkan mayoritas responden mengalami anemia yakni sebanyak 57 orang $(69,51 \%)$ sedangkan responden yang tidak mengalami anemia yakni sebanyak 25 orang (30,49\%). Distribusi makrosomia pada responden didaptkan mayoritas sampel tidak mengalami makrosomia yakni sebanyak 62 orang $(75,61 \%)$, dan yang melahirkan anak makrosomia sebanyak 20 orang (24,39\%). Mayoritas responden adalah ibu yang tidak melahirkan anak gemelli yakni sebanyak 67 orang $(81,71 \%)$, sedangkan ibu yang memiliki anak gemelli sebanyak 15 orang (18,29\%). Untuk distribusi kepatuhan ANC didaptkan mayoritas responden tidak patuh melakukan ANC yakni sebanyak 64 orang $(78,05 \%)$, dan responden yang patuh melakukan ANC sebanyak 18 orang $(21,95)$. Untuk distribusi berdasarkan perdarahan postpartum didapatkan mayoritas responden mengalami perdarahan postpartum primer yaitu sebanyak 55 orang $(67,07 \%)$, dan yang mengalami perdarahan postpartum sekunder sebanyak 27 orang $(32,93)$

Tabel 2. Analisis Hubungan Kepatuhan ANC Dengan Kejadian Anemia

\begin{tabular}{|c|c|c|c|c|c|}
\hline \multirow[t]{2}{*}{ Parameter } & \multicolumn{2}{|c|}{ Anemia } & \multirow[t]{2}{*}{ Total (n) } & \multirow[t]{2}{*}{$\%$} & \multirow[t]{2}{*}{ P-Value } \\
\hline & Iya & Tidak & & & \\
\hline Tidak patuh & 50 & 14 & 64 & 78.05 & \multirow{3}{*}{0,004} \\
\hline Patuh & 7 & 11 & 18 & 21,95 & \\
\hline Total & 57 & 25 & 82 & 100 & \\
\hline
\end{tabular}

Berdasarkan Tabel 2, diketahui bahwa Hasil analisis bivariat hubungan kepatuhan ANC dengan kejadian anemia menggunakan uji Chi-Square dengan convidende interval 95\% (derajat kemaknaan 0,05) Diperoleh nilai $\mathrm{p}<0,05$. Hal ini menunjukkan bahwa terdapat hubungan bermakna secara statistik antara kepatuhan ANC dengan kejadian anemia.

Tabel 3. Hubungan Kepatuhan ANC Dengan Kejadian Makrosomia

\begin{tabular}{|c|c|c|c|c|c|}
\hline \multirow[t]{2}{*}{ ANC } & \multicolumn{2}{|c|}{ Makrosomia } & \multirow[t]{2}{*}{ Total (n) } & \multirow[t]{2}{*}{$\%$} & \multirow[t]{2}{*}{ P-Value } \\
\hline & Iya & Tidak & & & \\
\hline Tidak patuh & 15 & 49 & 64 & 78.05 & \multirow{3}{*}{0.759} \\
\hline Patuh & 5 & 13 & 18 & 21.95 & \\
\hline Total & 20 & 62 & 82 & 100 & \\
\hline
\end{tabular}

Berdasarkan Tabel 3, diketahui bahwa Hasil analisis bivariat hubungan kepatuhan ANC dengan kejadian makrosomia menggunakan uji Chi-Square dengan convidende interval 95\% (derajat kemaknaan 0,05) Diperoleh nilai $\mathrm{p}>0.05$. Hal ini menunjukkan bahwa tidak terdapat hubungan bermakna secara statistik antara kepatuhan ANC dengan kejadian makrosomia. 
Tabel 4. Hubungan Kepatuhan ANC Dengan Kejadian Gemelli

\begin{tabular}{lcccccc}
\hline \multirow{2}{*}{ Parameter } & \multicolumn{2}{c}{ Anemia } & Total (n) & $\%$ & P-Value \\
\cline { 2 - 6 } & Iya & Tidak & & & & \\
\cline { 2 - 6 } Tidak patuh & 9 & 55 & 64 & 78.05 & \multirow{2}{*}{0.085} \\
\hline Patuh & 6 & 12 & 18 & 21.95 & \\
\hline Total & 15 & 67 & 82 & 100 & \\
\hline
\end{tabular}

Berdasarkan Tabel 4, diketahui bahwa Hasil analisis bivariat hubungan kepatuhan ANC dengan kejadian gemelli menggunakan uji Chi-Square dengan convidende interval 95\% (derajat kemaknaan 0.05) Diperoleh nilai $\mathrm{p}>0.05$. Hal ini menunjukkan bahwa tidak terdapat hubungan bermakna secara statistik antara kepatuhan ANC dengan kejadian gemelli.

\section{PEMBAHASAN}

Antenatal Care merupakan suatu program pelayanan kesehatan bagi ibu hamil yang di buat oleh pemerintah untuk mengurangi angka morbiditas dan mortalitas ibu dan anak.(3) salah satu masalah atau komlikasi kehamilan yang paling sering menyebabkan kematian ibu adalah perdarahan postpartum.(5)

Kepatuhan ANC dapat menghindarakan ibu dari semua komplikasi atau masalah kehamilan seperti anemia, BBLR, KEK, makrosomia, gemelli, perdarahan dan lain lain. Dengan ANC tidak patuh ibu hamil akan lebih beresiko mengalami komlikasi dibandingkan ibu yang patuh melakukan ANC. Sebagian besar sampel yang mengalami Anemia pada penelitian ini memiliki riwayat ANC yang tidak patuh.(7)

Hasil penelitian ini sejalan dengan penelitian yang dilakukan oleh Riyanto et.al (2012) yang mendapatkan hubungan anatar kelengkapan ANC dengan kejadian Anemia.(8) selain itu, penelitian ini juga sejalan dengan penelitian yang dilakukan oleh Veny Nurmasari et al. (2018) yang mengatakan bahwa ibu hamil yang melakukan pelayanan ANC lengkap akan memiliki resiko anemia lebih rendah dibandingkan dengan ibu hamil dengan ANC tidak lengkap.(9)

Anemia merupakan suatu kondisi dimana seorang ibu memiliki kadar $\mathrm{Hb}$ dibawah normal yaitu pada trimester 1 dan $3<11 \mathrm{gr} / \mathrm{dl}$ dan pada trimester $2<10,5 \mathrm{gr} / \mathrm{dl}$. Pada ibu hamil anemia bukan hal yang tidak mungkin terjadi ini disebabkan karena darah selain terpakai untuk tubuhnya juga dialirkan kepadaa anaknya untuk metabolisme dan perkembangan anaknya, sehingga jika di barengi dengan konsumsi makanan yang kurang bergizi akan membuat tubuh kekurangan zat besi sebagai bahan pembentukan hemoglobin. Keadaan ini pada dasarnya dapat dicegah dalam melakukan ANC karena pada saat seorang ibu hamil melakukan ANC akan mendapatkan tablet penambah darah $(\mathrm{Fe})$ sehingga dapaat mencegah terjadinya anemia saat hamil.(8) Selain itu, dengan taat melakukan ANC ibu hamil juga akan mendapatkan konseling gizi yang tepat serta pendidikan kesehatan yang memadai sehingga faktor resiko terjadinya anemia dapat ditekan.(9)

Analisis hubungan kepatuhan ANC dengan kejadian makrosomia mayoritas sampel pada penelitian ini tidak memiliki anak yang makrosomia. Hasil penelitian ini sejalan dengaan penelitian yang dilakukan oleh Susianti et al. (2016) yang menyebutkan bahwa makrosomia terjadi paling bnyak disebabkan oleh 
berat badan ibu yang melebihi normal (obesitas) baik sebelum maupun saat hamil sehingga saat pertumbuhan dan perkembangan janinnya akan mendapatkan asupan gizi atau makanan yang berlebih sehingga berat badan bayi lahir juga akan melebihi batas normal. Selain itu, multiparitas dengan riwayat melahirkan bayi besar juga bisa menjadi faktor resiko terjadinya makrosomia karena secara teori berat badan bayi yang dilahirkan akan selalu meningkat pada kelahiran berikutnya. Keadaan makrosomia juga bisa disebabkan oleh penyakit diabetes yang diderita saat hamil, karena pada saat ibu mengalami diabetes kadar gula darah ibu tinggi dan semua darah secara normal akan mengalir kejanin sehingga dapat digunakan janin dalam perkembangan dan pertumbuhannya.(10) Namun, makrosomia bisa saja dipengaruhi oleh kepatuhan ANC karena salah satu pelayanan ANC adalah konseling masalah gizi ibu hamil sehingga dengan melakukan pemeriksaan ANC ibu hamil dapat mengetahui makanan - makanan yang bergizi dan sesuai dengan kebutuhannya. Pada pemeriksaan ANC pertambahan berat badan ibu hamil juga akan dinilai sehingga dapat dilakukan skrining terlebih dahulu terkait berat badan bayi yang dikandung.(3)

Pada analisis hubungan kepatuhan ANC dengan kejadian gemelli, mayoritas sampel pada penelitian ini memiliki jumlah anak satu. Hasil penelitian ini sejalan dengan penelitian yang dilakukan oleh Rizka et al. (2019) dimana pada penelitiannya disebutkan bahwa faktor atau penyebab tersering menyebabkan terjadinya gemelli adalah riwayat keluarga (genetik). Dimana ibu yang memiliki riwayat keluarga melahirkan anak gemelli akan lebih berpotensi melahirkan anak gemelli dibandingkan dengan ibu yang tidak mempunyai riwayat keluarga nelahirkan anak gemelli.(11)

\section{KESIMPULAN}

Berdasarkan hasil analisis bivariat maka dapat disimpulkan bahwa terdapat hubungan signifikan antara tingkat kepatuhan ANC dengan kejadian anemia, namun tidak terdapat hubungan signifikan antara tingkat kepatuhan ANC dengan kejadian makrosomia dan gemelli

\section{DAFTAR PUSTAKA}

1. Kementerian Kesehatan RI. Rencana Strategis Kementerian Kesehatan Tahun 2015 - 2019. Sekretariat Jendral Kementerian Kesehatan RI, 2015.

2. WHO. Monitoring Helath For SDGS 2017

3. Kementerian Kesehatan RI. Profil Kesehatan Indonesia Tahun 2017. Kementerian Kesehatan RI, 2018

4. Dinas Kesehatan Provensi Sulawesi Selatan. Profil Kesehatan Provinsi Sulawesi Selatan Tahun 2016. Media Kesehatan, 2017;1:347

5. Ramadhan, Jihan Wafda, dkk. Profil Pasien Hemorrhagic Postpartum di RSUP Dr. M. Djamil Padang. Jurnal Kesehatan Andalas, 2019;8(2):46 
6. Puspita, Ratna, dkk. Risk Factors of Postpartum Hemorrhage in Bondowoso District, East Java. Jouenal of Maternal and Child Health, 2017;02(02):176-86.

7. Rifdiani, Izfa. Pengaruh Paritas, BBLR, Jarak Kehamilan dan Riwayat Perdarahan Terhadap Kejadian Perdarahan Postpartum. Jurnal Berkala Epidemiologi, 2016;4(3):384-95.

8. Riyanto, dkk. Faktor - Faktor Yang Berhubungan Dengan Anemia Ibu Hamil di Kabupaten Lampung timur. Jurnal Kesehatan Metro Sai Wawai, 2012;V(9):5-8.

9. Nurmasari Veny, Sri Sumarmi. Hubungan Keteraturan Kunjungan Antenatal Care dan Kepatuhan Konsumsi Tablet Fe Dengan Kejadian Anemia Pada Ibu Hamil Trimester III di Kecamatan Maron Probolinggo. Amerta Nutrition, 2019;3(1):46.

10. Susianti. Faktor - Faktor Yang Berhubungan Dengan Makrosomia di RSUD Sawerigading Palopo. Susianti, 2016;6:77-84.

11. Arzil, Rizka, dkk. Kembar Siam (Dicephalus Paraphagus Dibracius). Jurnal Kesehatan Andalas, 2019;8(2):468. 